\title{
LI YANG CRAZY ENGLISH METHOD: BETWEEN CHINESE AND JAVANESE CULTURE
}

\author{
Maya Dania \\ Gadjah Mada University
}

\begin{abstract}
Nowadays English is spoken everywhere. English has become the world's Lingua Franca. Many jobs demand English as their first priority to select applicants. Schools push their students to learn English since it becomes the most favorite qualification for getting job. Many English courses are built in order to facilitate people's needs to understand English. Nevertheless, along with the world's request on English, many people in non-spoken English country still feel unfamiliar to it. It creates some anxiety and terror to them.
\end{abstract}

In China, there is a unique language-learning method to deal with English fear. It is called Crazy English. Li Yang, a man who initiated this method, believed that many Chinese were facing a very difficult time on learning English. He then coined an extra-ordinary way to make people proficient in English by especially emphasizing the speaking and pronunciation skills. Based on his method, he taught his students to read English words loudly and quickly, and also told them to imitate the sound of English words. He had already proved himself that by conducting this methods he was able to get the second-highest score on his National English Exams after failing it thirteen times: For Li Yang, the only main obstacle on learning English was the Chinese's traditional culture that made people afraid to talk. He suggested people to overcome English by shouting and speaking it loudly, so that all the embarrassment could fade away.

Comparing with Chinese, Javanese people have also the same problem related to the afraid-to-talk culture. Based on writer's experience in class, many students feel shy and unconfident to speak English. It makes a very tough problem when learning English is not followed by the courage to speak.

This paper is aimed to investigate the Li Yang Crazy English method and evaluate its potential aspect to be applied in many English classes in Indonesia, particularly in Java region. The analysis of this paper is taken from literature research and it is also supported by performing in-class observation. As the result of the research, this paper will give a clear 
understanding about Li Yang Crazy English and also its potential aspect to be applied in Indonesia by giving three main considerations, such as : 1) The general evaluation of positive and negative aspects from Li Yang English method, 2) The similar cultural background (East culture) of Chinese and Javanese, 3) The readiness of Indonesian teacher to apply this method.

Keywords: Li Yang Crazy English Method, Chinese Culture, Javanese culture

\section{Introduction}

It is indisputable that English has become the world's most spoken language. English becomes the world's second language since it is applied and used widely throughout nations: As the world's second language, English becomes the compulsory language which is required on job vacancies as well as on study field. The urgent to comprehend English is getting higher each day, since many job opportunities demand English as their prior requirement. The chance to get a -scholarship also depends on the applicants' ability to make communication in English. Generally, English can be considered as the global language that brings the key for global communication.

Despite the important feature on understanding English, many people find it so difficult to leam English. This is a typical situation for the nations who become the non-western EFL (English as First Language) countries such as Indonesia. Although English has already been taught in formal classes, many students still feel not familiar with its words. English is a nightmare, moreover when it becomes one of the prerequisites curriculums for students who wish to pass the school examination.

This situation generates the rapid grow of ESL (English for Second Language) business. Nowadays, many English courses are available in many places nearby the neighborhood. Each course offers different method to be applied in the classroom. But still, none of them is able to provide a significant strategy that can attract people to comprehend English. Based on that situation, it will be very beneficial to explore new kind of methods and evaluate new possibilities to find a new way to teach English for students more effectively.

Lately in China, there is a booming movement related with English teaching method. This method is popular in China and even got recognition from many China's newspaper and appreciated by some researchers in America. This method called "Crazy English". It was created by a man nained Li Yang. The method was able to magnetize people and became one trend in China. 
This paper tries to evaluate Li Yang's Crazy English method and see its potention to be applied in Indonesia. It is a necessary to explore new teaching method related with English learning since Indonesia still becomes a growing country and not so many people are eligible to comprehend English as their second language. The analysis for this paper is taken from literature data and it is also carried out in-class observation to accomplish a clear understanding from the subject that is introduced on this paper.

\section{Discussion}

\section{On Li Yang's Crazy English Method}

\section{a. What is Li Yang's Crazy English Method?}

Crazy English method is a way of teaching English for students whose living in non western EFL countries, particularly in China, created by Li Yang. It is popular because of its unusual method that gives more emphasizes on speaking skill than another skills in order to master English. The name of Crazy English was given by Li Yang. He chose the word "crazy" to reflect his belief that everything in life should be done with whole-hearted passion and abandon. Crazy English employs two primary components: physical and mental engagement. Both are intrinsic to the uniqueness of Li's method (Woodward, 2006:3).

In secondary school, Li Yang was a poor student with nearly failing grades. By chance, $\mathrm{Li}$ achieved exam scores that were high enough to enter Lanzhou University. At Lanzhou University, where he studied mechanical engineering and English, Li's academic achievements remained below average. In his first two years, he failed thirteen exams, mostly in English courses. Irritated with his progress, Li decided to make a major change to his ineffective study habits. Focusing on his English courses, he formulated a new method of learning and practicing spoken English. Li then tried to speak up his English and began to read English aloud. The more he practiced and the louder he spoke, the more confident he became. Li would shout English passages and class exercises, focusing his vocal energy on trees, lampposts, or even the unsuspecting pigeon. After only four months of using his shout-aloud method of learning English, Li felt confident and capable (Woodward, 2008:9).

$\mathrm{Li}$ then believed that the only way to comprehend English was just a method in breaking down a common barrier to language learning for especially Chinese students, namely, the fear of "losing face." The fear of losing face is a widespread obstacle to language learning in China because many students are 
worried about making oral mistakes in front of others, especially native English speakers, that they give up speaking altogether. A major reason for this problem is also that English classes in China tend to focus on reading and writing, rather than speaking. This results in Chinese students potentially mastering English grammar, but with acquiring limited proficiency in pronunciation and verbal fluidity (Woodward, 2008:7).

A similar understanding also was expressed by Liang (1996). He considered that if students haven't laid a concrete foundation for phonetics, this will directly affect learning words, drills and grammar. Along with that, if students have problems with words, then they can not organize proper sentences; if they can not construct a simple sentence, then they can't

construct a compound sentence; if their listening is poor, then they can not speak good English and this causes insufficient reading then writing difficulties (Liyang, 1996:7-9). In other words, basis areas such as phonetics, grammar and vocabulary;" probably providing an explanation to help many learners. In general, the key features of the successful learning strategies promoted by Li Yang's Crazy English can be sum up as follow:

1) Learning should occur for a purpose;

2) Learners should be confident that they can achieve their leaming goals;

3) English is a language, not a course, and the language should be used; and there should be a belief that "everybody can do it".

4) In promoting the learning of English, $\mathrm{Li}$ Yang encourages groups of learners to develop confidence by chanting that they wish to learn to speak perfect English.

(Zhang, 2008:2-3).

\section{b. How does Li Yang Apply His Method?}

Li's method on teaching English is simply described as "speak loudly and practice a lot". His method is especially emphasized on speaking and promunciation, or in general, he ask the student to read aloud English quickly until they can blurt it out. Li believes that Chinese students have no problem writing, they have no problem reading. That's why he triggers their power of speaking. $\mathrm{Li}$ believes that learning a language requires direct participation, just like learning a sport: "If you want to be a good swimmer, you have to jump in the water, conquer the fear, and survive. You cannot just sit beside the swimming pool, taking notes" (interview with Kirpal Singh, 2003). 
Mainly, Li teaches English by making the students imitating standard pronunciations. Student can have a good command of English by enhancing their spoken English first. It means that the Crazy English package does not include grammar, vocabulary, reading comprehension, writing, or listening comprehension. Indeed, pronunciation is only a small portion in foreign language leaming, but it affects our assessment on how well our overall ability, it further affects students' academic performance in leaming (Wang, 1996:56).

Therefore, Li Yang has only three rules for participation in Crazy English: Speak Loud, Speak Fast, and Speak Clearly. To improve pronunciation, Li emphasizes the repetition of phrases, words, and syllables, so that the tongue and the brain become accustomed to making new sounds. Li calls this "Tongue-Muscle Training" or working the "International Muscle," and says, "The tongue is an important organ for speaking. Some muscles in the tongue used to pronounce English sounds have withered in Chinese so we need to shout to restore them" (Liu Yumei, 2001). Another way that Li Yang demonstrates the proper pronunciation of words is his use of hand/arm movements that are supposedly coordinated to specific vowel and consonant sounds. In Crazy English lectures, Li will introduce a word to his audience and, after repeating the word several times, tell the audience to put their hands in the air and copy his movements. They attempt to coordinate their voices and hands to produce an accurate pronunciation (Onos, 2008).

In addition to teaching proper pronunciation, Li Yang also encourages his students to show charisma when speaking English. He believes that a full and weighty voice is necessary to prove one's skill in the English language. There are currently 200 million Chinese at secondary school who are bored with tests, and $\mathrm{Li}$ is still trying to change the way people learn to speak English. Li explains that this method is a new method for Asian people, who are shy and introverted. He believes that his method can give people confidence very quickly. He tries to simplify English for common people. Therefore, Li Yang can't be described as just an English teacher, but he's also a motivational expert. (Gallager, http:/www. independent.co.uk/news/world/asia/crazy-englist-how-chinas-languageteachers-became-big-celebrities-1777545.html,2009).

\section{c. Notes on Li Yang's Crazy English}

It is obvious that in the process of leaming the teacher's role is particularly important. Foreign language learning classrooms are a fertile ground for frustration, anxiety, embarrassment and humiliation. A smile, a nod and a word of encouragement from teacher will surely belp students build confidence and 
develop an interest in the course (Rivers, 1964: 92). In Li Yang's Crazy English, the teacher has role to especially teach phonetics and pronunciation with full of motivation if students are to achieve a better outcome. This makes the Li Yang's Crazy English method becomes popular in gaining people's attention and spirit to learn English.

One of Li Yang's commonly publicized goal for Crazy English is to teach about three hundred million Chinese to speak perfect English. The psychological component of the Crazy English method is closely related to its didactic emphasis on speech improvement. Li frequently shouts one of his favorite motivational slogans, "Crazy English! Crazy life! Crazy world! I love this crazy game, so let's go!" The "Crazy" in Crazy English signifies Li Yang's desire for students to have passion in their studies and to fulfill their dreams by giving over $100 \%$ of themselves to their personal goals, without the fear of failure (Woodward, 2006: 96). Ironically, good standard pronunciation is probably not a main component for many good language leamers in other cultures where pronunciation is more relative. By only asking students to memorizing particular sound, they will hardly make communication with people who speak almost unrecognizable English due to their difference accent of pronunciation.

Moreover, Li Yang only says English words without giving any further details about the context in how, when, where, and what condition does one word should and could be applied. This makes words and phrases that Li teaches are random and useless. Without receiving much direction as to the appropriate context for such phrases, the student is left to imagine where and when to use the sentences that they labored to pronounce perfectly. The combining of words that are unrelated in meaning and promunciation is another problem of Crazy English. In one event, Li asked the user to repeat, "Lucky, nice, face, no, no smoking, talk, famous, dangerous, enjoy your stay." These words obviously make no sense when spoken together, but student without an extensive knowledge of English may think that they are learning a sentence or important word combinations (Woodward, $2008: 24$ )

Students of Crazy English class will get benefit by enhancing their performance on speaking and commiting a perfect pronunciation. However, they will benefit more from the lesson if they have a working knowledge of English vocabulary and grammar. It is because in Crazy English method, when Li Yang chooses words and phrases to practice, he does not provide vocabulary lists or grammar notes. He assumes that there is no need to waste time on translation or context. In the lectures, Li may translate a word or a phrase into Chinese, but this is often to emphasize the feeling behind the word by reminding the audience of the 
emphasis in a Chinese translation. From this, $\mathrm{Li}$ Yang is succeed to make the students feel that the vocabulary and grammar used in Crazy English lectures are simple. But in other hand, Crazy English lectures rarely contain full English sentences. For example, Li will string

together words like, "Good. City. Busy," and "Great. Make. Dangerous. Famous." Usually the words are chosen to emphasize a similar pronunciation, like the "a"a" sound in the second set of words here; yet, at other times, the words seem to have no similarities in pronunciation, as with "good" and "city/busy." The few full English sentences that Li does articulate in his lectures are usually not intended for repetition by the audience, but are merely spoken to impress the students with Li's pronunciation skills. Very rarely is English text displayed in the lectures, beyond the signs for vowel and consonant sounds, and no writing is required (Woodward, 2008:25-27).

Indeed, students are not able to make a solely understanding and comprehension into English. But, they still can enjoy Li's charisma and incorporation of edutainment in his English lectures, as well as the opportunity to scream and clap to loud music.

\section{Possibility to Apply Li Yang's Crazy English}

a. Comparing Chinese and Javanese Cultural Background

1. Overview on Chinese Culture Toward English

Li Yang actually disagrees with the traditional method of teaching English. He believes that embarrassment can be a great obstacle to learn. His most familiar motivation for students is "enjoy losing face," or in full statement "put your face in your pocket and cry out in English with me, so that you don't lose it in the future!" More than learning to speak English, Crazy English is a method to overcome common psychological obstacles, like bashfulness and introversion. Li says, "Chinese are typically shy. Shouting can help erase their mental obstacles, excite their mouths and ears, and strengthen their confidence and concentration" (Yumei, 2001). Many Chinese are afraid of losing their composure in public and especially in the presence of a native English speaker. If they could overcome this fear, they would have a more successful language learning experience.

Li originally developed the shouting-method for learning English because he himself was too shy and introverted to dare speaking English aloud. Li believes that most Chinese are brought up with modesty and a lack of confidence they are afraid of losing face in front of family, friends, educators, and even strangers. 
Common English teaching methods in China reflect this fear of failure and accommodate students by allowing them to learn English without practicing speaking, preparing dialogues, or giving individual oral presentations. The goal of Crazy English is to avoid embarrassment, as well as learning to speak accurately and effectively (Woodward, 2006:3).

Losing face is a serious matter which will, in varying degrees, affect one's ability to function effectively in society. Face is lost when the individual, either through his action or that of people closely related to him, fails to meet essential requirements placed upon him by virtue of the social position he occupies. In contrast to the ideology of individualism, the question of face frequently arises beyond the realm of individual responsibility and subjective volition ( $\mathrm{Ho}, 1976)$.

In Chinese classrooms, students are expected to speak English at a certain level of fluency. If they feel that their spoken English skills are not up to the same level with the standards set by the teacher, then they may be so afraid of failure and they probably decide to give up speaking in class. The same fear is reflected in encounters with foreigners; if a Chinese person feels that his or her English is too poor, he or she may not brave to commit a conversation with a native English speaker. By denying speaking practice, the fear of losing face becomes a vicious cycle, wherein language skills deteriorate with fear, and fear increases with deteriorating capability (Woodward, 2008:28).

Inherited social dynamics also play a role in silencing classroom discussion and participation in large groups (May, 2005). In traditional Chinese hierarchies, youths are not encouraged to show a mastery of skills that is greater than the skills of their adult counterparts. For example, a child should avoiding speaking English to his grandfather if his grandfather's English skills are inferior to his own. If the child did so, he would be showing disrespect. This dynamic was also true for the male-female relationship; traditionally, Chinese women should not flaunt intelligence or acquired skills before less accomplished men. Fortunately, a more balanced society has limited this harsh gender gap. In addition to age and gender, social status also plays a role in determining who speaks and who does not speak in a classroom setting. Many English language courses in China are open to the public, resulting in a diverse student demographic. Taxi drivers, police officers, and doctors may all attend the same class. If this is the case, then the taxi driver may be disinclined to contribute as much to the discussion or dialoguing. He may feel that it is not his place, or he simply may lack the confidence, to speak in front of those who are more educated than he is (Woodward, 2008:26). 
This message seems especially important in East Asian countries, as one of the major hindrances to activities such as learning foreign languages is the fear of losing face. "Face" is not a strong concept in the West, where students are usually told to "shoot for the stars," "try your best," "be an individual," and "have no fear." In the East, "face" is what is expected of someone under certain conditions and according to certain relationships. "Losing face" is not meeting the standards expected in a given situation. The fear of losing face is so great for many Chinese that it becomes debilitating (Woodward, 2008:29).

\section{Overview on Javanese Culture Toward English}

Javanese culture is described as the culture that is possessed by the native people who live in the central and east part of Java island (Suseno, 2001:11). Javanese culture is differed from any other form of cultures in Indonesia, noticed from their different historical background as well as their language (Koentjaraningrat, 1960: 88). Javanese culture holds their family system based on bilateral descent system (considering the family system based on both father's and mother's line) (Ayatrohaedi, 1989b: 138).

Javanese society, makes a differentiation among their society members. They divide their class levels into upper and lower class. While the upper class belongs to king family, academician, and the religion leader, the lower class belongs to those who work in land and market. Javanese society system is generated by functional consciousness, especially based on the social hierarchies that they have provided, and this creates a solid system that shapes the social norms and values that Javanese people holds the most.

Javanese people strongly believes in the existence of balance. It means that every activity that they do, it must not be done againts the law of order. As possible as they can, Javanese people will strongly avoid the state of chaos and choose the silent act in order to avoid conflicts. In fact, the Ethics becomes the indicator and measurement for the society to identify wheater someone deserves to be called Javanese or not (Muhibin, 2006:20). Hilder Geertz states that there are two basic norms of Ethics that Javanese people holds :

a) The Norm of Harmony

Harmony is defined as a state where every part in one organization is arranged well and balance in every way. For Javanese people, their social mechanism is heavily relied on the harmony as their first rule in the society. The harmony is created by a condition where everyone is obeying and appreciating 
each other. This is reflected by the attitude named "gotong royong" (working together to achieve one aim) and "tepa selira" (understanding others' interest and showing consideration to the difference) (Endraswara, 2003b: 38). Self-interest and opinion are basically admitted in Javanese society, but they are tied by the harmony norm and their position is no as high as the social-interest. Social disorder and conflicts are solved and avoided by applying the harmony value and it is also applied on Javanese people's daily life. To maintain and to occupy the social order is a virtue for Javanese people (Suseno, 2001:58).

\section{b). The Norm of Respect}

Respect is shown in the way Javanese people consider themselves and their position towards the other's based on the social hierarchies that have already been established and admitted in their society. For Javanese people, it is a necessity to maintain and to keep their position and role in their society, as well as to divide their privileges and obligations in the society system (Suseno, 2001:60). This is indicated by the attitude named "sungkan". Hildred Geertz argues that the meaning of "aji" and "ngajeni" is equal with the mearing of respectful and respecting in English translation. In the other hand, Koentjaraningrat describes respect in more detail way. He thinks that respect is not simply describes as a feeling towards the other's position, but it's also related with the feeling of superiority and inferiority (Riyani, 2005: 75). The norm of respect is the generator for the Javanese People to maintain their relationship among others. Since respect becomes the main generator for maintaining people's relationship, Javanese people arrange the general rule that bonded the whole role in their society into one main frame named "tata krama" (Endraswara, 2003a: 83). In the system of "tata krama", the interaction and relation between two person is placed according to their status and their position in the society. Usually, :tata krama" is placed to arrange the relationship between "kasepuhan" (old people) and "kanoman" (young people) based on their link in the family tree (Geertz, 1982: 22).

In general, these two norms teach Javanese people to always respect to the social hierarchies that have already been established in their society and these also require that Javanese people must act appropriately according to their function and role in their socuety. The norm of harmony and respect greatly influence the way that Javanese people think and do, indeed also organize the way Javanese people make interaction as well as the way Javanese people make interaction in their society. These two norms become the main core of Javanese philosophy that shape the values and beliefs that characterize the behavior of Javanese people (Suseno, 2001:38). 
From the very early age, the Javanese parents will teach their children to give respect to the other people. The preach is usually consisted on three main principles, which are known as : "wedi" (afraid), "isin" (embarrassed), "sungkan" (reluctant).

These three principles are related each other and can't be left partly. Even though the practice of these three principles is place in social context, but the value that those princilples bring is rooted in Javanese people's psychology (Endraswara, 2003a: 83). "Wedi" is thought in order to make the children feel afraid of someone who has higher status, position, or even older than them. Children will get punishment if they are dare to rebel and act outside the rules. Thus, children will obtain compliment if they obey the social rules and apply their respect to the other people (Suseno, 2001: 63). Along with that, children is also taught to have "isin" feeling. It means that they must behave according to their status and position in the society. It is such an embarrasement for Javanese people to act overlapping in front of many people. They will get critics and even waming if they dare to do unappropriate behavior in front of many people (Suseno, 2001: 64). Meanwhile, "sungkan" feeling is related with what Koentjaraningrat called as superiority and inferioirty feeling. When a Javanese people face another person, they must consider their position to decide what kind of treatement that they will do to that enother person. Javanese people is obligated to treat someone according to their role and status. If someone is placed in a higher level of status, then, the "sungkan" feeling is applied, in order to show tribute and honor (Riyani, 2005:90).

From that three principles that the Javanese hold, it can be seen that Javanese people is strongly concern about their attitude, related with the judgement and perspectives that the society will give on them. Rooted from the same East culture with Chinese, "face" is also an important thing to be kept for Javanese people. The fear of losing face in front of many people, implanted by the root of Javanese principle that obligate its people to maintain the feeling of "wedi", "isin", and "sungkan".

In Javanese classrooms, students are expected to speak English at a certain level of fluency too. The situation is not different too far from the Chinese's. Based on the writer's observation in four Conversation classes, many students felt embarrassed to speak in front of many person, since they were afraid to make mistake in front of the class. They have the same fear that Li calls "fera of losing face". In addition, they couldn't present a fluent English in the classroom since they couldn't practice English in their daily activity. For Javanese people, as well as Chinese, youth must respect the adult and old person by giving their humbleness with not showing any mastery in front of them. To show any mastery is front of 
adults or respectful persons mean that they intend to scratch the older's face. If they do so, it means that they have break the rule of superiority and inferiority in their society. Especially in Javanese culture. breaking the rule means that generating the chaos condition which is absolutely prohibited

\section{b. Evaluation of Li Yang's Crazy English}

The matter of social status and hierarchies in East culture are the main obstacles that haunted the foreign language learning process. Students need to be motivated, and if it is necessary, they also need to be released from the cultural boundaries that limit their ability to learn foreign language. Silence culture that happens in the classroom is mainly caused by the cultural demand that has already shaped students' personality and thought. Unfortunately, this silence culture and cultural boundaries problems still happen in Indonesia's English classrooms. This gives prove that in learning English, several factors, beside books and literature sources, are needed to be considered

Several factors have also been considered important in second language learning. Among them are method of instruction, age, aptitude and certain affective variables such as attitude, motivation and empathy. Examination of these three factors: attitude, motivation, and empathy, may provide fruitful insights into the complex problem of success in second language acquisition (Schumann, 1995 : 222).

Li Yang's Crazy English provides a pragmatic way on mastering English through the practice of speaking and read the English words aloud. Li thinks that the best method to comprehend English as the second language is by shouting it and speaking it up. But, research into the effectiveness of various instructional methodologies has shown no method to be superior to any other (Smith and Berger, 1968)

Indeed, related with the cultural background that barrier people's ability on learning English, students need to be motivated and influenced psychologically so that they are able to catch the English words fastly. In fact, motivation becomes the first step for student to getting familiar with English. Motivation (Gardner and Lambert, 1972) relates to the goals of second language learning. In terms of psychological distance, the integrative motivated learner would seek maximum proximity in order to meet, talk with, and perhaps even become like the speakers of the target language. Consequently, if the learner's goal were mere survival, he might maintain a good deal of psychological distance between himself and the speakers of the target language. Another source of psychological distance may be 
the relative rigidity of the learner's ego boundaries (Guiora, 1972). Some experimental evidence indicates that people who have ego permeability, for instance, the ability to partially and temporarily give up their separateness of identity, are better second language learners (Schumann, $1995: 266$ ).

Li Yang's Crazy English may be useful to be applied in Indonesia's English classrooms since it can help the teacher to initiate students' motivation on learning English. But it also means that the teacher must be ready to give not only lesson, but also motivation to all the students. Teacher is demanded to perform not only knowledge but also ability to motivate. Teacher may apply the Li Yang's Crazy English on a class where speaking skill is essential. In most cases, the conversation class is such a challenging class, where the students are required to be active and perform their ability on speaking. The silence culture that the students psychologically endure, may become the teacher's obstacle to create a contented classroom. The taught in Li Yang's Crazy English that support the students to be $100 \%$ involve in classroom may bring benefit to light up the classroom's environment. Students will be asked to "Speak Loud, Speak Fast, and Speak Clearly" and this method will help them to practice their tounge so and they can also get used to pronounce English words.

Nevertheless, Li Yang's Crazy English method has a flaw that it fails to build a comprehensive understanding for the students in learning English. This method doesn't provide a knowledge about grammar and structure comprehension. But, based on its focus on speaking ability, the teacher may take note and add some attitude to mend the lack that Li Yang's Crazy English experience. This principles may be useful to give broader picture for the teacher in order to make the speaking class become more competent and eligible:

(Adapted from Maclure and Hargreaves 1986, p.2)

1. Talk is purposeful. Through it we do things and get things done in collaboration with others. Assessment of talking and listening should reflect this.

2. A successful communicator needs to master a range of competencies. Assessment should sample the variety and complexity of spoken language.

3. Oral language is important in all areas of the primary school curriculum. Talk assists learning in all school subjects. Assessment of oral language should make use of cross curriculum opportunities.

4. Talking and writing are integral parts of a student's overall communicative ability. Student often have to read about a topic, talk about it with others, and write a report that draws on both the reading and the discussion. Some 
assessment procedures should be multi-modal and should involve sequential activities.

5. Talking and listening occur together. Assessment procedures should not separate them artificially.

6. Spoken language is sensitive to context. Speakers are always influenced by such contextual factors as the subject matter, the social roles and relationship of the people involved in the interpretation of the "feedback" given and received. Assessment of oral communication must recognize and take account on these factors.

7. Attitudes and oral language performance are interrelated. Some attention should be given to the assessment of pupil's attitudes towards talking and listening in various school and school-related settings.

(Dweyer, $1994: 96$ )

In addition, it's not enough to only put self-motivation and attitude in learning English, but teacher should also build empathy that will entirely help the student to grasp their comprehension toward English. Increasing the student's empathy will lead to more effective second language communication in several ways. First of all, empathy tends to limit the use of cultural stereotypes. It would call on the language leamer to approach the native speaker as an individual who also happens to be a member of a different culture group. Reducing cultural stereotypes has often been cited as an important goal of foreign language teaching; empathy training is one means of helping to achieve this goal. A second benefit to the language leamer would be an increased ability to observe the reactions of a native speaker during a conversation and thereby obtain feedback as to whether their message was understood exactly as intended. They can then practice to utilize this feedback for self-correction (Horwitz, 1995 : 115).

\section{Conclusion}

In spite of the lack that Li Yang's Crazy English method undergo, it can stil] be applied in Indonesia's English class. First consideration is, in general, Indonesia's English class has the same obstacle that also happens in China's English class. This paper is limited to observe Indonesia's English class from Javanese culture perspective. Based on the research, the Javanese culture meets the same cultural background and the same basis problem that blockade the learning process in English class. This problem known as "fear of losing face" culture. Li Yang's Crazy English method will help the students to maintain their fear by performing self-motivation and psychological stimulus to crack the cultural barrier. Second consideration is, even Li Yang's Crazy English method doesn't 
provide a way for student to understand English Grammar and structure, it is still helpful for the teacher to teach English in Conversation and Basic class, where English is introduced as the first step and speaking skills is essential to perform. In order to make the class more fruitful, some additional notes may be required. It needs not only self-motivation from the teacher, but also attitude and empathy. According to those two considerations, the third consideration can be accomplished that the English teacher in Indonesia is able and ready to apply $\mathrm{Li}$ Yang's Crazy English method, with the commitment that English teacher is not only playing the role as a teacher, but also the motivator for the students. Again, teacher's work for finding the best way to teach English is not done yet.

\section{References}

CSL 505 Linguistic Studies 2, 1995, the University of South Australia.

Schumann, John H.; "Affective Factors and the Problem of Age in Second Language Acquisition", p.222.

Horwitz, Elaine K., Horwitz, Michael B., "Bridging Individual Differences: Empathy and Communicative Competence", University of Illinois, Champaign-Urbana, p. 115

CSL 510 Field Experience, Distance Education Centre, 1994, University of South Australia.

Dweyer, John "Assessing Oral Language”, p.96

Endraswara, Suwardi, 2003, "Budi Pekerti dalam Masyarakat Jawa", . Hanindita, Yogyakarta.

$$
\text { 2003," Falsafah Hidup Jawa", Cakrawala, Jakarta. }
$$

Geertz, Hildred. 1982. "Keluarga Jawa", PT. Temprint, Jakarta.

Ho, David Yau-fai., 1976, "On the Concept of Face", The American Journal of Sociology.

Koentjaraningrat, 1994, "Kebudayaan Jawa", Balai Pustaka, Jakarta.

Larsen, D.N and Smalley, W.A. 1972, "Becoming Bilingual: A Guide to Language Learning", New Canaan, Conn: Practical Anthropology.

Liang, Y., 1996, "On Problems of Two Extremes in English Teaching in Junior Secondary Schools", Foreign Language in Schools.

Maclure, M. \& Hargreaves, M. 1986, "Speaking and Listening: Assessment at Age 11 ",APU, NFER-Nelson, Windsor

Mufti, Riyani, 2005, Skripsi : "Penggambaran Etika Jawa dalam Relief Wiracarita Ramayana di Candi Prambanan", Unnes Semarang, Jawa Tengah. 
Suseno, Franz-Magnis, 2001, “Etika Jawa”, Gramedia, Jakarta.

Wang, Q. Z., \& Li, S. H., 1996, "Exploration a few issues on English course in primary school", Foreign Language Teaching in Schools .

Woodward, Amber. R., 2008, "A Survey on Li Yang's Crazy English, Sino-Platonic Paper" (April, ed.180), Philadelphia.

Woodward, Amber R., 2006, "Learning English, Losing Face, and Taking Over: The Method (or Madness) of Li Yang and His Crazy English", Sino-Platonic Papers, (February, ed. 170), Philadelphia.

Woodward, Amber R., 2006, “Survey on Li Yang and Crazy English" (Survey. Oct.), Philadelphia.

Yang Yunbao, 2008, “What Crazy.English Can Tell Us?”, International Education Studies (Vo.1, No,2), School of Educational Studies (Bundoora Campus), La Trobe University, Melbourne, Australia.

Zhang, Z. D., 2000, "Theories and Schools of Foreign Language Teaching - Methodology in China", Science Publishing Press, Beijing. .

\section{Internet Sources :}

Galagher, Sean, 2009, "Crazy English: How China's Language Teachers Became Big Celebrities", http://www.independent.co.uk/news/world/asia/crazyenglish-how-chinas-language-teachers-became-big-celebrities1777545.html, posted August 29.

Osnos, Evan, 2008, "Letter from China : Crazy English, The National Scramble to Learn a New Language Before the Olympics", http://www.newyorker.com/reporting/2008/04/28/ 080428fa fact osnos, posted April 28.

Zhan, Ni. 2005, "Li Yang Crazy For English." China Today. http://www.dowriwithup.com /china/2004_03_14_archive.html, posted May. 